\title{
Análise da Ocorrência de Seis Grupos de Coleoptera em Dois Ecossistemas Perturbados Ecologicamente
}

\author{
Tatiana Galdino-da-Silva ${ }^{\bowtie}$, Henrique Trevisan \& Acacio Geraldo de Carvalho
}

Universidade Federal Rural do Rio de Janeiro, e-mail: tatgaldinolm@gmail.com (Autor para correspondência ${ }^{\bowtie}$ ), hentrevisan@gmail.com, acacio@ufrrj.br.

\section{EntomoBrasilis 9 (3): 187-192 (2016)}

Resumo. Embora os insetos sejam considerados relevantes nos processos ecológicos, esses organismos constituem um dos grupos menos registrados entre os animais levantados na fauna brasileira. Também são entendidas como insuficientes às pesquisas que investigam sua ocorrência em ambientes com características ecológicas distintas. Nesse contexto, o objetivo deste trabalho é analisar a ocorrência de seis táxons de insetos (Scolytinae, Platypodinae, Bostrichidae, Cerambycidae, Curculionidae e Nitidulidae) em duas áreas com características ecológicas distintas, pastagem e fragmento florestal. Objetiva-se também proporcionar uma discussão que fomente o entendimento da ocorrência destes insetos em relação às características do ambiente, gerando dados que sinalizem a possibilidade de bioindicação em trabalhos futuros com estes organismos. As coletas foram realizadas semanalmente em Ipiabas, distrito de Barra do Piraí, RJ, através da instalação de oito armadilhas de impacto, modelo semifunil, sendo quatro armadilhas em cada ecossistema, distantes 50 metros uma da outra. As amostras foram obtidas no período de maio de 2012 a maio de 2013 . Coletouse 4.796 coleópteros, sendo que 3.275 (67,9\%) indivíduos foram capturados no fragmento florestal e 1.521 (32,03\%) em área de pastagem. A subfamília Scolytinae foi mais freqüente no pasto durante o período seco, enquanto a família Nitidulidae apresentou maior freqüência no fragmento florestal e no período chuvoso. Dentre os grupos avaliados, os nitidulídeos demonstraram ocorrer distintamente entre os ambientes, indicando que esta família responde de forma mais evidente às mudanças ambientais entre os ecossistemas avaliados, em relação aos outros grupos taxonômicos identificados neste levantamento.

Palavras-chave: Armadilha de impacto; flutuação populacional; fragmento florestal; insetos; pastagem.

\section{Analysis of the Occurrence of Six Groups of Coleoptera in Two Ecologically Disturbed Ecosystems}

Abstract. The aim of this study was to analyze the occurrence of six groups of insects (Scolytinae, Platypodinae, Bostrichidae, Cerambycidae, Curculionidae and Nitidulidae) in a pasture area and forest fragment, in order to provide a discussion that fosters the understanding of the occurrence of these insects in function of the assessed ecosystem, generating data that signal the possibility of bioindication in future work with these organisms. The samples were obtained weekly in Ipiabas, a district of Barra do Pirai, RJ, by the installation of eight impact traps, semifunil model, in the study areas, being four traps in the pasture's area and four in the forest fragment, respecting the distance of 50 meters between them. Samples were collected from May 2012 to May 2013. A total of 4,796 beetles were collected, of which 3,275 (67.9\%) individuals were captured in the forest fragment and $1,521(32.03 \%)$ in the pasture. The subfamily Scolytinae was more frequent in the pasture and during the dry season, while the Nitidulidae family showed higher frequency in the forest fragment and in the rainy season. Among the studied groups, the nitidulídeos had greater variation in occurrence's patterns, indicating that this family has the potential to be used as an indicator of environmental quality.

Keywords: Forest fragment; insects; impact trap; pasture; population dynamics.

(U) insetos têm uma grande importância ecológica, entretanto segundo BATISTA (2003), esses organismos são um dos grupos menos documentados entre os animais terrestres, constantemente omitidos dos diagnósticos e levantamentos de fauna do Brasil. Ainda, também são consideradas parcas, ou não conclusivas, as informações e pesquisas pertinentes ao estudo da ocorrência e dinâmica desses organismos em ecossistemas impactados pela ação do homem.

Nesse contexto, discute-se que o isolamento, fragmentação ou mesmo a antropização do ambiente alteram a estrutura florestal, ocasionando, portanto, a interrupção de processos biológicos que mantêm a biodiversidade e o funcionamento do ecossistema, como a polinização, dispersão de sementes e reciclagem de nutrientes. Como grande parte destes processos é mediada pelos artrópodes, verifica-se que a fragmentação florestal afeta não só a abundância e a diversidade de insetos como também modifica, direta e indiretamente, as interações ecológicas com outros organismos (MurCiA 1995).

Dentre os invertebrados, observam-se alguns estudos, em que os insetos têm sido investigados com o intuito de encontrar subsídios, para que não apenas se conheça a sua diversidade, mas também gerem informações que possam servir de base para discussões que avaliem condições de perturbações ecológicas, face às atividades antrópicas (HumpHeReY et al. 1999).

Sendo assim, o estudo destes organismos pode ser considerado adequado em pesquisas que objetivam a avaliação de impacto ambiental e de efeitos de fragmentação florestal. Pois, além de ser o grupo de animais mais numerosos do globo terrestre, possuem elevadas densidades populacionais, apresentam ampla diversidade de espécies e de habitats, bem como grande variedade de habilidades para dispersão e seleção de hospedeiros e de respostas à qualidade e quantidade de recursos disponíveis (Thomazini \& Thomazini 200o). Diante desses fatos, o uso de insetos como indicadores biológicos tem sido sugerido como um meio eficiente para se investigar o quanto o ecossistema Mata Atlântica está sendo afetado pelas atividades antrópicas (FrEITAS et al. 2003).

Neste sentido, torna-se oportuno e necessário considerar pesquisas que analisem a dinâmica populacional desses organismos em ambientes que sofreram processos de perturbação ambiental, visando à geração de informação que possa fomentar 
T discussões sobre bioindicação nestes habitats, face aos padrões de ocorrência observados.

Sobre esse raciocínio, convém levar em consideração nestas pesquisas, às características peculiares de cada grupo. Nesse sentido, a ordem Coleopteraéconsiderada a mais expressiva dentre a classe Insecta, pois compreende cerca de aproximadamente 360 mil espécies descritas, sendo 40\% dos insetos e 30\% dos animais (Lawrence \& Newton 1995). Portanto, diante desses atributos, este grupo em especial, é considerado importante indicador da qualidade do ambiente, além, também, da ampla quantidade de nichos ecológicos que ocupam (Costa 1999).

Perante o exposto, este trabalho objetivou avaliar a ocorrência de seis grupos de coleópteros (Scolytinae, Platypodinae, Bostrichidae, Cerambycidae, Curculionidae e Nitidulidae) em dois ecossistemas com características ecológicas distintas, pastagem e de fragmento florestal de Mata Atlântica, ambos localizados no município de Barra do Piraí, distrito de Ipiabas, RJ.

\section{MATERIAL E MÉTODOS}

A pesquisa foi realizada em uma área de fragmento de mata e de pastagem situadas a $22^{\circ} 21^{\prime}$ de latitude e $43^{\circ} 52^{\prime}$ de longitude, distrito de Ipiabas, município de Barra do Piraí no estado do Rio de Janeiro. Trata-se de uma área de Floresta Estacional Semidecidual e faz parte de uma região considerada pelo Ministério do Meio Ambiente como área prioritária para conservação de invertebrados (BRASIL 2000).

Foram instaladas, a 1,30 $\mathrm{m}$ do solo, quatro armadilhas de impacto em cada ambiente, oito no total, distando $50 \mathrm{~m}$ uma da outra, conforme recomendações de (Bossoes 2011). O modelo deste equipamento, denominado semifunil (Figura 1, 2 e 3), foi construído com material reciclável seguindo as orientações de (CARVAlho \& TREVISAN 2015).

Cada armadilha foi iscada com álcool $96{ }^{\circ} \mathrm{GL}$ (Figura 1f), substância também utilizada no frasco armazenador (Figura 1d), para conservação dos indivíduos que foram atraídos e capturados. Os equipamentos permaneceram no campo no período de maio de 2012 a maio de 2013. As coletas foram realizadas semanalmente, momento o qual a substância atrativa era renovada nas armadilhas. painel interceptador "semifunil"; (c) funil coletor; (d) frasco armazenador; (f) mangueira porta isca; (e) Arame fixador.
Os insetos coletados foram levados ao Laboratório de Entomologia Florestal, do Departamento de Produtos Florestais da UFRRJ, onde foram tabulados por data, local de coleta e grupo taxonômico (Scolytinae, Platypodinae, Bostrichidae, Cerambycidae, Nitidulidae e Curculionidae) e de morfoespécies no caso da família Nitidulidae. A escolha para monitoramento destes grupos taxonômicos foi realizada em função de serem insetos atraídos pelo etanol utilizado como isca nas armadilhas, sendo, portanto, uma especificidade do modelo de armadilha utilizada neste levantamento (Bossoes 2011; CARvalHo \& TREvisan 2015). Ainda, sobre Scolytinae, Platypodinae, Bostrichidae e Cerambycidae, estes grupos são considerados os principais que proporcionam danos tanto em florestas nativas como exóticas no Brasil, sendo, portanto, necessários mais estudos a cerca desses táxons, no que tange, inclusive, o conhecimento sobre sua ecologia (MONTEIRo \& GARLET 2016).

A ocorrência dos grupos de coleópteros em cada área de estudo foi avaliada através dos cálculos de frequência e constância, seguindo a classificação de Silveira Neto et al. (1976), que consideram indivíduos constantes, os que estão presentes em mais de 50\% das coletas; acessórios, entre 25 e 50\%; e acidentais, em menos de $25 \%$ das coletas.

Os valores absolutos, utilizados nos cálculos percentuais de ocorrência, foram comparados pelo teste de qui-quadrado a $5 \%$ de significância. Ainda, para os dois grupos, Nitidulidae e Scolytinae, cuja ocorrência demonstrou-se mais expressiva que os demais, adotou-se também o teste de Mann-Whitney (5\% de significância) para a análise de variâncias. Teste adotado pelo fato dos valores não terem assumido distribuição normal (Lilliefors $5 \%$ de significância) e serem provindos de dois grupos amostrais.

A diversidade de morfoespécies da família Nitidulidae foi analisada através dos índices de Shannon-Weaver e de Simpson, segundo MagurRan (1988), com o auxílio do programa Bioestat, versão 5.o. E a similaridade entre as áreas estudadas, no que se refere a esta família, foi discutida através do índice de similaridade de Jaccard.

A análise da sazonalidade, no que se refere à ocorrência de Nitidulidade e Scolytinae, foi realizada pela confecção de gráficos de linha, onde se relaciona o número médio de indivíduos capturados com a época do ano em que foram capturados em cada ambiente.

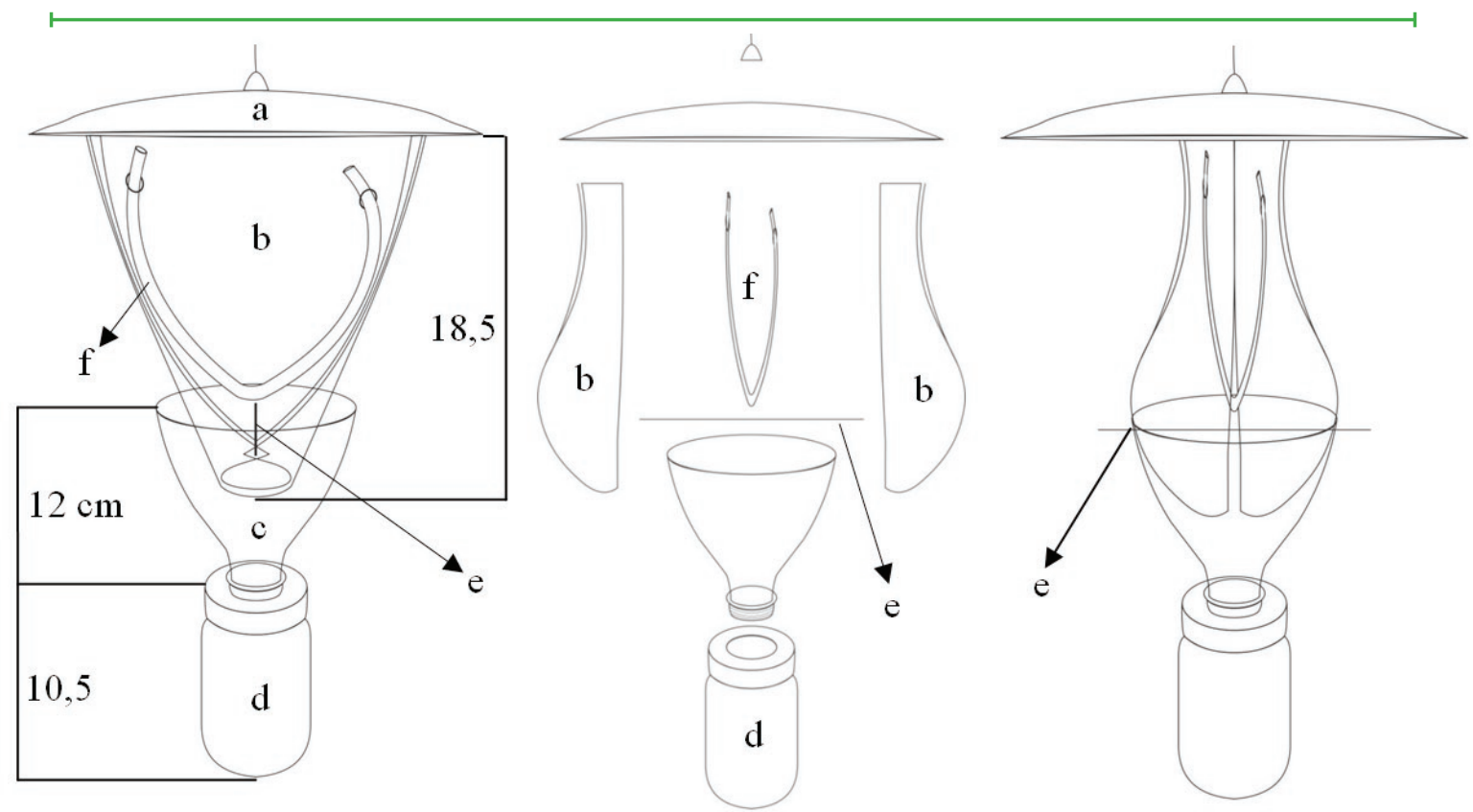

Figura 2. Vista lateral das peças: (b) Painel interceptador; (e) Arame fixador; (f) Mangueira porta isca; (d) Frasco armazenador.
Figura 3. Vista lateral da armadilha montada: (e) eixo fixador (arame rígido)

Fonte: Carvalho \& Trevisan (2015) 


\section{RESULTADOS E DISCUSSÃO}

Foram coletados 4796 coleópteros, sendo que 3275 (67,9\%) indivíduos foram capturados em fragmento de mata e 1521 (32,03\%) em ambiente de pasto. Estes resultados estão de acordo com MEDRi \& LOPEs (2001) que, observaram no norte do Paraná, em ambiente de mata, um número de besouros quase três vezes maior do que o número destes insetos na pastagem. Cabe ressaltar que MEDRI \& LOPES (2001) realizaram os levantamentos no mesmo bioma avaliado neste trabalho, a Mata Atlântica. No entanto discordam de THomazin (2002) que ao avaliarem a entomofauna em ambientes de floresta, capoeira e pastagem no sudeste acreano, bioma Amazônico, registraram maior número de coleópteros no pasto. Sendo assim, essa análise pode sugerir que variações na ocorrência de insetos, em florestas e pastagem, podem ser influenciadas pelo bioma onde estão sendo realizados os levantamentos. Cabendo a essas colocações pesquisas suplementares.

Scolytinae e Nitidulidae foram os grupos mais coletados dentre os demais, no entanto somente para Nitidulidae registrou-se diferença significativa no número total de indivíduos para cada ambiente (Figura 4).

Valores seguidos de mesma letra, entre barras do mesmo táxon, não diferem pelo teste de qui-quadrado $(\mathrm{p}<0,05)$

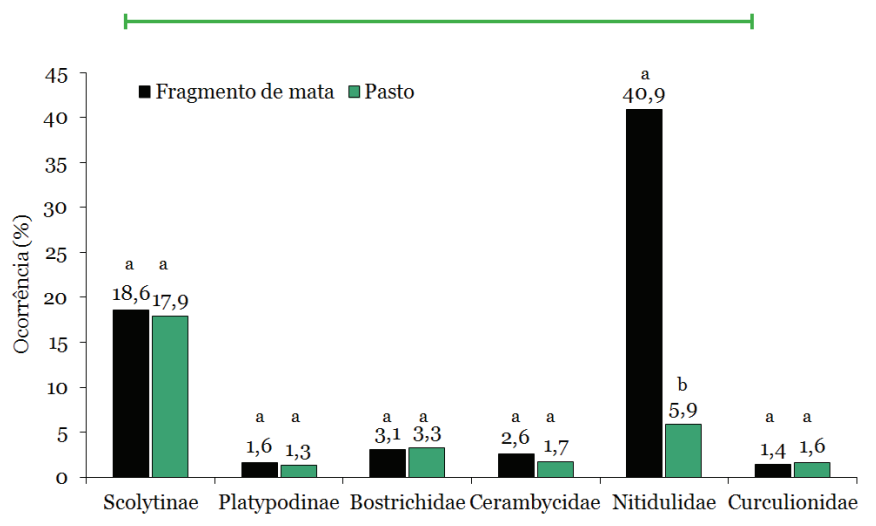

Grupo

Figura 4. Porcentagem de indivíduos, por grupo, capturados com armadilha semifunil, no fragmento de mata e no pasto no período de maio de 2012 a maio de 2013, no distrito de Ipiabas, Barra do Piraí, RJ.

Em relação à constância, no fragmento de mata, a subfamília Scolytinae e a família Nitidulidae demonstraram-se constantes e a subfamília Platypodinae e as famílias Bostrichidae, Cerambycidae e Curculionidae foram classificadas como acessórias.

No ambiente de pasto apenas a subfamília Scolytinae apresentouse constante, e as famílias Bostrichidae e Nitidulidae foram qualificadas como acessórias. Platypodinae, Cerambycidae e Curculionidae foram classificadas como acidentais (Tabela 1).

Tabela 1. Constância dos grupos capturados com armadilha semifunil no período de maio de 2012 a maio de 2013, no distrito de Ipiabas, RJ.

\begin{tabular}{ccc}
\hline \multirow{2}{*}{ Grupo } & \multicolumn{2}{c}{ Constância } \\
\cline { 2 - 3 } & Fragmento de mata & Pasto \\
\hline Scolytinae & $82,21 \%$ constante & $76,44 \%$ constante \\
\hline Platypodinae & $29,80 \%$ acessória & $17,31 \%$ acidental \\
\hline Bostrichidae & $39,42 \%$ acessória & $25,97 \%$ acessória \\
\hline Cerambycidae & $35,58 \%$ acessória & $24,04 \%$ acidental \\
\hline Nitidulidae & $72,11 \%$ constante & $37,50 \%$ acessória \\
\hline Curculionidae & $25,00 \%$ acessória & $23,08 \%$ acidental \\
\hline
\end{tabular}

Sobre esses registros, Clemente (1995) argumenta que a alta porcentagem de espécies acidentais, em comunidades florestais, indica que o ambiente oferece resistência à proliferação dessas espécies e que as espécies classificadas como constantes estão de fato estabelecidas dentro da comunidade.

Diante da argumentação de Clemente (1995), pode-se supor que no fragmento de mata, os escolitíneos e os nitidulídeos estão estabelecidos. Já no ambiente de pastagem, apenas os escolitíneos conseguiram se estabelecer. Ainda, pode-se supor também, que o ambiente de pastagem oferece à família Nitidulidae algum tipo de resistência que não ocorre no ambiente de mata.

O número médio de indivíduos da subfamília Scolytinae não apresentou diferença significativa em relação a sua ocorrência na mata e no pasto. Já para a família Nitidulidae observou-se um número médio de indivíduos significativamente superior no fragmento de mata em comparação ao pasto (Tabela 2).

Tabela 2. Número médio de indivíduos, \pm desvio padrão, de Scolytinae e Nitidulidae $\mathrm{m}$ armadilha semifunil no período de maio de 2012 a maio de 2013, no distrito de Ipiabas, RJ.

\begin{tabular}{ccc}
\hline \multirow{2}{*}{ Grupo } & \multicolumn{2}{c}{ Ambiente } \\
\cline { 2 - 3 } & Fragmento de mata & Pasto \\
\hline Scolytinae & $4,21 \pm 4,06 \mathrm{a}$ & $4,0 \pm 4,80 \mathrm{a}$ \\
Nitidulidae & $9,25 \pm 8,59 \mathrm{a}$ & $1,3 \pm 2,24 \mathrm{~b}$ \\
\hline
\end{tabular}

Valores seguidos de letras diferentes, na linha, diferem estatisticamente pelo teste de Mann Whitney a $1 \%$ de significância.

A família Nitidulidae demonstrou-se ocorrer de forma mais abundante na área de fragmento de mata. Este registro corrobora GonçaLVEs (2005) que ao pesquisar a estratificação vertical de coleópteros em diferentes fragmentos no sul de Minas Gerais, constatou que a família Nitidulidae ocorreu em maior abundância em todos os fragmentos avaliados.

Sendo assim, dentre as famílias da ordem Coleoptera consideradas nesta pesquisa, a família Nitidulidae foi a que apresentou maior capacidade em responder às mudanças ecológicas entre os ambientes avaliados. Isso sugere que este grupo demonstrouse com potencial para ser levado em consideração em pesquisas de bioindicação no que tange a avaliação de ecossistemas perturbados ecologicamente.

Devido a essa constatação, a ocorrência de indivíduos dessa família também foi analisada em nível de morfoespécie. Sobre essa estratégia, Oliver \& BeATtie (1996) relatam que inventários de morfoespécies podem ser utilizados substituindo o inventário das espécies, para viabilizar a comparação da riqueza entre as áreas ao longo do tempo e do espaço.

Dessa forma, foram registradas oito morfoespécies da família Nitidulidae, totalizando 1961 indivíduos no fragmento de mata e 280 indivíduos no ambiente de pasto. As morfoespécies sp.5, sp.7 e sp. 8 foram registradas tanto no fragmento de mata como no ambiente de pasto e as morfoespécies sp.1, sp.2, sp.3, sp.4 e sp. 6 ocorreram exclusivamente no fragmento de mata (Tabela 3). Sendo assim, observa-se que nenhuma morfoespécie ocorreu exclusivamente no ambiente de pastagem.

A diversidade de morfoespécies pode ser estudada com base na existência de dois componentes: a diversidade inventarial, que aborda a riqueza de espécies na sua simples expressão e a diversidade diferencial mede as diferenças na composição de espécies entre dois ou mais ambientes, ou em um mesmo ambiente ao longo do tempo (MARINONI \& GANHO 2006).

Nesse sentido a diversidade inventarial, ou diversidade alfa da família Nitidulidae é discutida através do índice de Simpson e de Shannon. Já a diversidade beta é analisada através do índice de Jaccard. 
Tabela 3. Número de morfoespécies de Nitidulidae capturadas em fragmento de mata e pasto no período de maio de 2012 a maio de 2013 em Ipiabas, RJ.

\begin{tabular}{ccc}
\hline \multirow{2}{*}{ Morfoespécie } & \multicolumn{2}{c}{ Número de morfoespécie } \\
\cline { 2 - 3 } & Fragmento de mata & Pasto \\
\hline Sp.1 & 71 & - \\
Sp.2 & 102 & - \\
Sp.3 & 107 & - \\
Sp.4 & 126 & - \\
Sp.5 & 203 & 13 \\
Sp.6 & 40 & - \\
Sp.7 & 802 & 150 \\
\hline Sp.8 & 510 & 117 \\
\hline Total & 1961 & 280 \\
\hline
\end{tabular}

Desta forma, o índice de Similaridade de Jaccard foi igual a o,37 demonstrando que a composição da família Nitidulidae no fragmento de mata e no pasto, é pouco similar.

A baixa similaridade na composição dos nitidulídeos entre as duas áreas, muito provavelmente tem relação com a diferença de microclima e de espécies vegetais presentes nos dois ambientes. Nesta explicação, pode residir o respaldo para a hipótese, anteriormente mencionada, sobre a resistência oferecida pelo ambiente de pasto, ao estabelecimento de Nitidulidae.

A análise dos índices de diversidade de morfoespécies de Simpson e Shannon para a família Nitidulidae indica que pelo índice de Simpson, a diversidade no ambiente de pasto é maior que a diversidade no fragmento de mata. Já o índice de Shannon, aponta que a diversidade no fragmento, é maior que no pasto (Tabela 4).

Tabela 4. Análise faunística da família Nitidulidae capturada com armadilha etanólica, em fragmento e ambiente de pasto no distrito de Ipiabas, RJ, no período de maio de 2012 a maio de 2013.

\begin{tabular}{ccc}
\hline Parâmetro & Fragmento de mata & Pasto \\
\hline Riqueza (S) & 8 & 3 \\
Índice de Simpson & 0,7428 & 0,5363 \\
Índice de Shannon & 0,7118 & 0,3655 \\
\hline$\longmapsto$
\end{tabular}

Diante dessa aparente contradição, MELO (2008) explica que um determinado índice de diversidade pode indicar que a comunidade A é mais diversa que a $\mathrm{B}$, enquanto outro índice indica o oposto. Isto ocorre devido ao fato de um índice ter dado maior relevância para riqueza de espécies enquanto o outro índice de diversidade ter dado maior relevância para equabilidade. Entendendo equabilidade como uma medida de ponderação, relacionando a distribuição de indivíduos amostrados com o número de espécies. Comunidades com alta equidade possuem baixa dominância entre as espécies (Cullen et al. 2006). Esse padrão foi observado neste trabalho.

Onúmero médio de insetos coletados no período chuvoso (outubro a março) e seco (abril a setembro) percebe-se que os coleópteros não apresentaram grande variação em termos de número médio de indivíduos por período (Figura 5). Esse registro contrasta com Teixeira et al. (2009), que na Mata do Mergulhão (RJ) registrou $61,8 \%$ dos indivíduos no período chuvoso e $38,2 \%$ de indivíduos no período seco. Discorda também de Azevedo et al. (2011), que na Floresta Nacional do Araripe observaram maior número de coleópteros no período seco. Dorval (2002) observou também no Mato Grosso, menor atividade de coleópteros em períodos de maior pluviosidade.

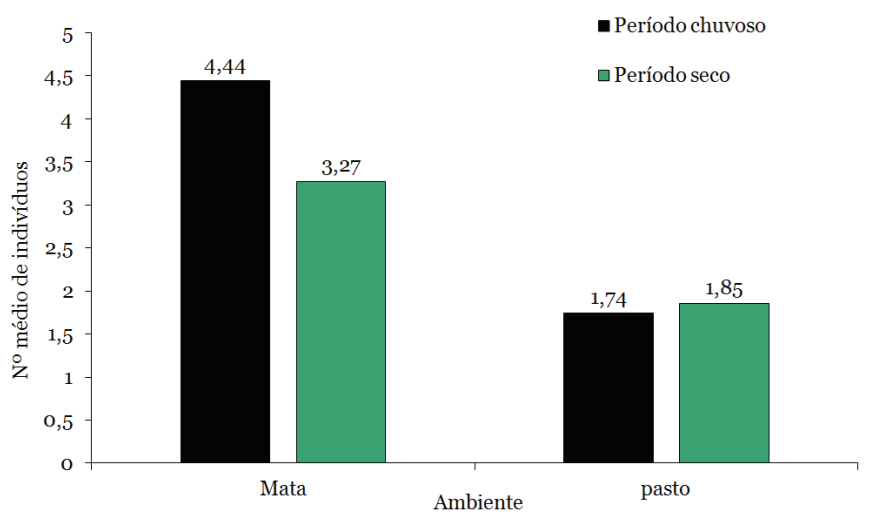

Figura 5. Número médio de indivíduos dos coleópteros capturados com armadilha semifunil no ambiente de mata e pasto, no período seco e chuvoso, em Ipiabas, RJ.

No entanto, referente à sazonalidade da família Nitidulidae no fragmento de mata, observou-se evidente frequência superior no período chuvoso (outubro a março) quando comparado com o período seco (abril a setembro), tendo o pico populacional ocorrido em janeiro (Figura 6). Contudo, AzEvedo et al. (2011) na floresta nacional do Araripe, observaram resultados diferentes, pois a família Nitidulidae ocorreu com maior freqüência no período seco.

Em Scolytinae não foi observada influência evidente do período seco e chuvoso em sua ocorrência neste ambiente, sendo o padrão sazonal semelhante em ambos os períodos (Figura 6). Esse registro concorda com GuSMÃo (2011), que ao quantificar o número de escolitíneos no cerrado, também não encontrou diferença significativa do número de indivíduos em relação à época do ano.

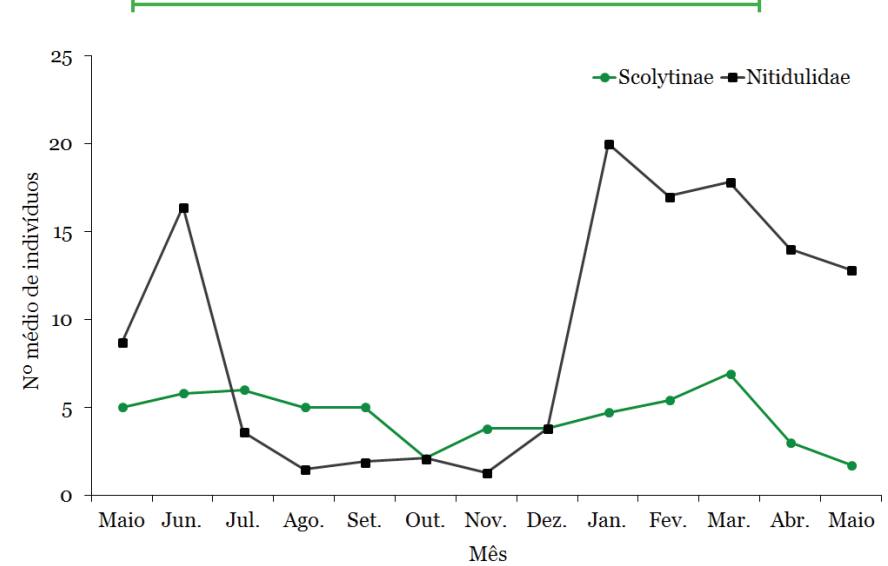

Figura 6. Sazonalidade de indivíduos da subfamília Scolytinae e família Nitidulidae coletados no fragmento de mata no período de maio de 2012 a maio de 2013 no distrito de Ipiabas, Barra do Piraí, RJ.

No pasto verificou-se padrão de frequência diferente em relação ao observado no fragmento de mata. A família Nitidulidae revelou manter uma população inferior durante todo o período analisado, em relação à Scolytinae. Neste ambiente, Scolytinae ocorreu com evidente frequência superior durante o período seco, apresentando pico populacional no mês de julho (Figura 7). Gusmão (2011) obteve o mesmo resultado em povoamento de eucalipto, no Mato Grosso.

Diante dos resultados registrados nas condições ambientais nas quais esse levantamento foi realizado, conclui-se que os grupos Scolytinae, Platypodinae, Cerambycidae, Bostrichidae e Curculionidae demonstra ocorrer com padrão populacional semelhante entre o fragmento florestal e a pastagem. Já a família Nitidulidade demonstra ser mais sensível às variações ecológicas entre os habitats estudados, revelando claro padrão de ocorrência distinto entre ambientes, sugerindo, desta forma, que este grupo 
taxonômico responde às variações ecológicas dos ambientes de forma mais evidente em relação aos demais táxons considerados neste levantamento.

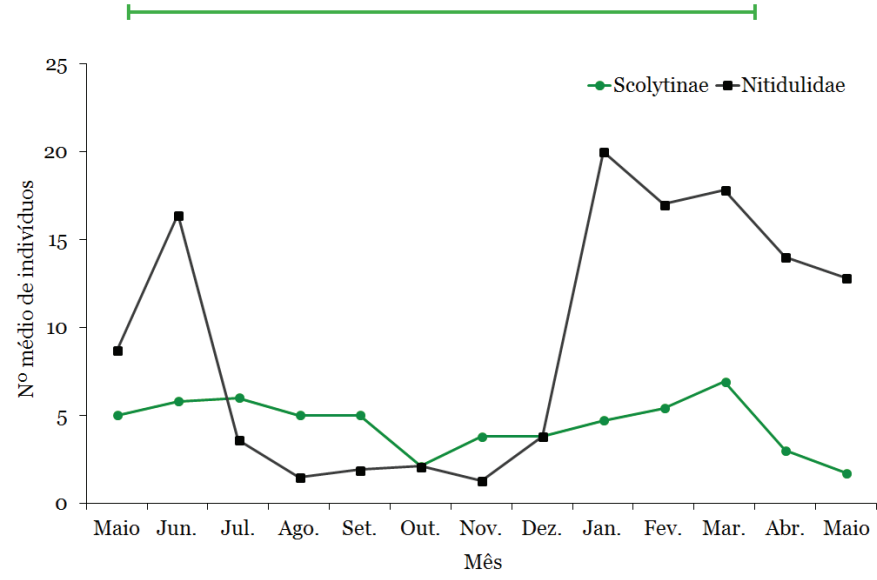

Figura 7. Sazonalidade de indivíduos da subfamília Scolytinae e família Nitidulidae coletados no ambiente de pasto no período de maio de 2012 a maio de 2013 no distrito de Ipiabas, Barra do Piraí, RJ.

\section{REFERÊNCIAS}

Azevedo, F.R, M.A.R. Moura, M.S.B. Arrais \& D.R. NERE, 2011. Composição da entomofauna da Floresta Nacional do Araripe em diferentes vegetações e estações do ano. Revista Ceres, 58: 740-748. doi: http://dx.doi.org/10.1590/s0034737x2011000600010.

Batista, M.A., 2003. Distribuição e dinâmica especial de abelhas sociais Meliponini em um remanescente de Mata Atlântica (Salvador, Bahia, Brasil). Dissertação (Mestrado em Ciências). FFCLRP-USP, $159 \mathrm{f}$.

Bossoes, R.R., 2001. Avaliação e adaptação de armadilhas para captura de insetos em corredor agroflorestal. Dissertação (Mestrado em Fitossanidade de Biotecnologia Aplicada), Universidade Federal Rural do Rio de Janeiro, $34 \mathrm{f.}$

Brasil, 2000. Ministério do meio ambiente, Fundação SOS Mata Atlântica, Fundação Biodiversistas, Instituto de pesquisas ecológicas, Secretaria do Meio Ambiente do Estado de São Paulo, SEMAD/Instituto Estadual de Florestas MG, Avaliação e ações prioritárias para a conservação da biodiversidade da Mata Atlântica e Campos Sulinos por Conservation International do Brasil, Brasília, $40 \mathrm{p}$.

Carvalho, A.G. \& H. Trevisan, 2015. Novo modelo de armadilha para captura de Scolytinae e Platypodinae (Insecta, Coleoptera). Revista Floresta e Ambiente, 22: 575-578. doi: http://dx.doi.org/10.1590/2179-8087.105114.

Clemente, A.T.C., 1995. Análise da população de Lepidoptera em comunidades florestais de Araucaria angustifolia, Eucalyptus grandis e Pinus taeda. Dissertação (Mestrado em Ciências Florestais), Universidade Federal do Paraná, 75 f.

Costa, C., 1999. Coleoptera, p 115-122. In: Brandão, C.R.F. \& E.M. Cancelo (Eds.). Invertebrados terrestres. Biodiversidade do Estado de São Paulo. São Paulo, FAPESP, 279 p.

Cullen Jr., L., R. Rudran \& C. Valladares-Padua (Eds.), 2006. Métodos de estudos em biologia da conservação e manejo da vida silvestre. Curitiba, Universidade Federal do Paraná, p. 169-179.

Dorval, A., 2002. Levantamento populacional de coleópteros com armadilhas etanólicas em plantios de eucaliptos e em uma área com vegetação de cerrado no município de Cuiabá, Estado de Mato Grosso. Tese (Doutorado em Engenharia Florestal), UFPR. Curitiba, $143 \mathrm{f}$.

Freitas, A.V.L., R.B. Francini \& K.S. Brown Jr. 2003. Insetos como Indicadores ambientais. p. 125-151. In: L. Cullen Jr, R. Rudran \& C. Valladares-Padua (Eds). Métodos de Estudos em Biologia da Conservação e Manejo da Vida Silvestre. Curitiba, UFPR, $652 \mathrm{p}$.

Gonçalves, P.P. \& J.N.C. Louzada, 2005. Estratificação vertical de coleópteros carpófilos (Insecta: Coleoptera) em fragmentos florestais do Sul do estado de Minas Gerais, Brasil. Ecologia Austral, 15: 101-110.

Gusmão, R. S., 2011. Análise faunística de Scolytidae (Coleoptera) coletadas com armadilhas etanólicas com e sem porta isca em Eucalyptus ssp em área de cerrado no município de Cuiabá M.T. Dissertação. (Mestrado em Ciências Ambientais e Florestais), Universidade Federal de Mato Grosso, CuiabáMT, $47 \mathrm{f}$.

Humphrey, J.W., C. Hawes, A.J. Peace, R. Ferris-Kaan \& M.R Jukes, 1999. Relationships between insect diversity and habitat characteristics in plantation forests. Forest Ecology and Management, 113: 11-21. doi: http://dx.doi.org/10.1016/ s0378-1127(98)00413-7.

Lawrence, J.F. \& E.B. Newton, 1995. Families and subfamilies of Coleoptera (with select genera, notes, references and data on family-group names). p. 779-1006. In: Papaluk J.F. \& Slipinski S.A. (Eds). Biology, phylogeny, and classificattion of Coleoptera. Varsóvia, Museum i Institut Zoologii, PAN, 1092p.

Magurran, A.E., 1988. Ecological Diversity and its Measurement. Princeton. Princeton University Press, 192 p.

Marinoni, R.C. \& N.G. Ganho, 2006. A diversidade diferencial beta de Coleoptera (Insecta) em uma paisagem antropizada do Bioma Araucária. Revista Brasileira de Entomologia, 50: 64-71. doi: http://dx.doi.org/1.0.1590/s008556262006000100009 .

Medri, I. M. \& J. Lopes, 2001. Coleopterofauna em floresta e pastagem no Norte do Paraná, Brasil, coletada com armadilha de solo. Revista Brasileira de Zoologia, 18: 125-133. doi: http://dx.doi.org/10.1590/s0101-81752001000500010.

Melo, A.S., 2008. O que ganhamos 'confundindo' riqueza de espécies e equabilidade em um índice de diversidade? Biota Neotropica, 8: 21-27. doi: http://dx.doi.org/10.1590/s167606032008000300001 .

Monteiro, M. \& J. Garlet, 2016. Principais coleobrocas de espécies florestais no Brasil: Uma revisão bibliográfica. Espacios, 37: 5p. Disponível em: <http://revistaespacios. com/a16v37n25/16372505.html>

Murcia, C., 1995. Edge effects in fragmented forests: implications for conservation. Trends in Ecology \& Evolution, 10: 58-62. doi: http://dx.doi.org/10.1016/s0169-5347(oo)88977-6.

Oliver, I. \& A.J. Beattie, 1996. Invertebrate morphospecies as surrogates for species: a case study. Conservation Biology, 10: 99-109. doi: http://dx.doi.org/10.1046/j.15231739.1996.10010099.X.

Silveira Neto, S., O. Nakano, D. Barbin \& N.A. Villa Nova, 1976. Manual de Ecologia dos Insetos. São Paulo, Agronômica Ceres, $419 \mathrm{p}$.

Teixeira, C.C.L., M. Hoffmann \& G. Silva-Filho, 2009. Comunidade de Coleoptera de solo em remanescente de Mata Atlântica no estado do Rio de Janeiro, Brasil. Biota Neotropica, 9: 91-95. doi: http://dx.doi.org/10.1590/s167606032009000400010 .

Thomazini, M.J., 2002. Flutuação populacional e intensidade de infestação da broca-dos-frutos em cupuaçu. Scientia Agrícola, 59: 463-468. http://dx.doi.org/10.1590/So10390162002000300009 .

Thomazini, M.J. \& A.P.B.W. Thomazini, 2000. A fragmentação florestal e a diversidade de insetos nas florestas tropicais úmidas. Rio Branco: Embrapa Acre, (Embrapa Acre. Documentos, 57), $21 \mathrm{p}$.

\section{Recebido em: $10 . v .2016$} Aceito em: 03.xi.2016 
Como citar este artigo:

Galdino-da-Silva, T., H. Trevisan \& A.G. Carvalho, 2016. Análise da Ocorrência de Seis Grupos de Coleoptera em Dois Ecossistemas Perturbados Ecologicamente. EntomoBrasilis, 9 (3): 187-192.

Acessível em: $\underline{\text { doi:10.12741/ebrasilis.v9i3.612 }}$
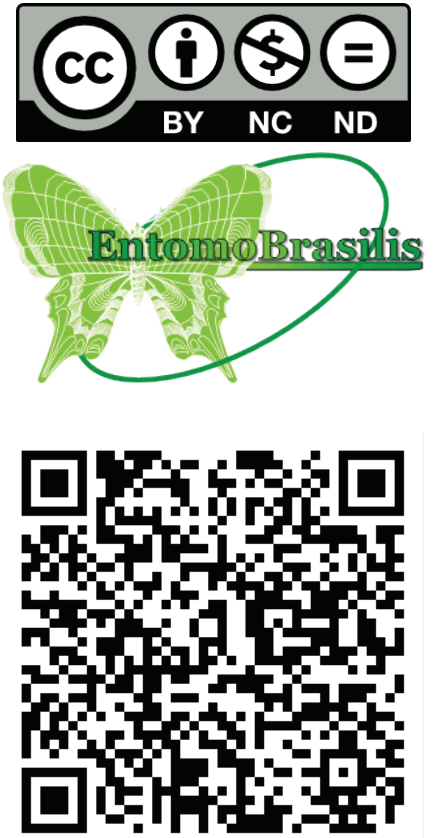